\title{
PERFORMANCE IMPROVEMENT METHODS
}

\author{
Niranjan Kumar T., Devadas Manoharan P. ${ }^{2}$ \\ ${ }^{1}$ Research Scholar, Faculty of Civil Engineering, Anna University, Chennai, India \\ ${ }^{2}$ Faculty of Civil Engineering, Anna University, Chennai, India. \\ E-mail : indianthambi@gmail.com
}

\section{Abstract}

Construction industry is clouded with uncertainties. Performance measurement becomes essential in order to study the complete characteristics of projects, so that ti will aid the project participants to achieve the goals in terms of meeting the planned schedule, controlling the deviation between budgeted cost and actual cost, achieving desired quality. The performance of a construction company is a function of the performance of its members. Higher the performance by individual members of the organization, higher will be the company performance. Profitability is viewed as the only criteria for success of any project in any organization. Productivity and its improvement provide less scope to assess the performance of any construction company. Performance measure needs to be carried out in all phases of the project systematically so that complete information about the performance leads to better decision making. Performance measurement is essential to assess the status of the project whether it will succeed or fail in achieving the desired objective. To aid better decision making tools such as AHP can be used for evaluating various criteria. Adetailed discussion about all the topics is covered in this paper.

Key words: Project Management, Decision Sports Systems, Analytic Hierarchy

\section{INTRODUCTION}

Infrastructure development is the second largest sector next to agriculture which India is concerned over the last two decades. Globalization and increased competitiveness has compelled India to a larger extent to concentrate more on infrastructure development. Many multi-nationals started opening up their facilities in India due to the geographical location and availability of cheap resource. India in a big way has opened up its market from creating a platform for software development to automobile manufacturing. In this present scenario our efforts in developing the infrastructure is hurdled by under utilization of human resource and poor performance due to improper process management in most of the projects. At sub-contracting stage due to improper training facilities many organizations are unable to exploit the resources properly. Lack of innovation, slow implementation of advanced technology, impedes the performance to a larger extent. This paper mainly focuses on study of various works done so far in performance measure. The study focuses on the personnel selection which is the most vital factor for any construction project. Decision makers on making a mistake in this will not only delay the project duration but also lead to failure in achieving the overall objective of the project.

\section{SCENARIO OF PERFORMANCE MEASURE}

In any project, project success is the ultimate goal of every construction project. To determine whether the project is completed as expected, final project performance must be evaluated (Barraza et al. 2004). Any project be it big or small should be completed with the planned budget and schedule. Cost overruns, time overrun, quality degradation in construction are common feature of projects. In spite of researchers attempting various studies on aspects of project performance still there is a vast gap between research and implementation of remedial measures. Will to change and adopt innovative techniques to some extent can to some extent reduce the poor performance.

The participants of the project are expected to possess required professional approach for the success. This is very much evident from the works which are not handled by professionals. According to Ireland (2004)., project costs would reduce by up to $10 \%$ and project times by up to $20 \%$ if project participants possessed the required professional standards. He further supported the achievement of good project performance through greater commitment to job performance.

In construction work we have both dependent and independent process. It is the responsibility of the planning department to identify the process involved and their dependencies. Since construction projects involve many interdependent work processes, job performance has to be measured on multiple dimensions, such as the quality and quantity of work (Borman 1991; Meyer et al. 1989).

As projects are unique in nature the participants keep on changing from time to time. Conflict resolution becomes a major problem. Since most of the participants are temporary except a few in project life cycle, conflicts do arise. To sort out the issues of control and conflict resolution a sound knowledge about the psychology of the participants becomes essential. Moore et al. (2003) stressed the role played by performance management in selection and development, which can alleviate interest and role conflicts by selecting newcomers with the attribute of conflict avoidance and by developing current staff with the ability to manage conflict resolution 


\section{PERFORMANCE PARAMETERS}

Viswesvaran (1993) who empirically identified ten popular component dimensions of job performance and stated that they comprehensively represented the entire job performance domain. They are productivity, quality, leadership, communication competence, administrative competence, effort, interpersonal competence, job knowledge, compliance with or acceptance of authority, and overall job performance. Dainty et al. (2003), based on their logistic regression analysis, found 12 competencies helping to distinguish between superior and average performers. These competencies are achievement orientation, initiative, information seeking, focus on client's needs, impact and influence, directiveness, teamwork and cooperation, team leadership, analytical thinking, conceptual thinking, self-control, and flexibility

Performance consists of seven dimensions: effectiveness, efficiency, quality, productivity, quality of work life, innovation, and profitability (Sink 1985). Effectiveness encompasses the attainment of the organization's objectives. Efficiency, which involves the utilization of resources, may be represented by the ratio of the resources expected to be consumed divided by the resources actually consumed. Labor productivity is a measure of efficiency. However, because of the laborintensive nature of construction, it is treated as a separate dimension. Quality involves doing things the right way the first time. The work performed must conform to the specifications established for the project. Innovation is the use of creativity by members of the organization. The identification and utilization of new and better materials, methods, procedures, etc., has positive benefits for the organization. Innovation allows a firm to remain competitive and provide a source of jobs. Productivity can be defined in a variety of ways depending upon the work being performed. It is typically defined as output/input, with output expressed in terms of physical units and input as man-hours required to produce the output. Quality of work life is concerned with the response of organizational members to the socio-technical aspects of the work and the organization. Quality of work life includes, among other issues, the autonomy people are granted in the performance of their work, the participation they are allowed in making decisions that affect them, and the social interaction allowed by the job.

The performance of a construction organization is a function of the performance of the members of that organization. High performance by individual members of the organization will result in high performance by the organization. Organizational performance, as well as individual performance, is multidimensional. (William F.
Maloney 1990). Profitability and productivity are necessary, but not sufficient, conditions for survival. It is possible for a firm profitable in the short run to go out of business for a variety of reasons. A productive firm is not always a profitable firm. Before proceeding to an examination of a performance analysis framework, it is necessary to develop an understanding of the multidimensional nature of performance.

\section{ARCHITECTS / ENGINEERS REQUIREMENT}

Performance of individuals directly or indirectly aids the success of the project. A Framework available from Malcolm Baldrige National Quality Award (MBNQA) place great emphasis on the management of human resources in a more complete way. Section 4.4 of the Baldrige framework focuses on employee involvement/ participation, compensation and rewards, and regular feedback. The performance of the project to a major extent depends upon the knowledge of the individuals who handle the project. Most of the projects be it small or big are handled by professionals either architect or an engineer. Success or failure is merely a function of their performance. It is their knowledge and experience which matters a lot compared to any other factor. about the fine details provided in the project. They are like the stern in a ship. In a contractor-led Design Build (DB) project, the design responsibility is usually undertaken by in-house architects and engineers, or external consultants engaged by designer/builders. Prior to engaging a prospective architect or engineer (AE), an valuation of his or her potential performance should be carried out.

A formal evaluation of parameters such as job knowledge, design quality, job experience, and communication skills is usually done. This evaluation includes a wide range of criteria that often consists of quantitative and qualitative information. The process remains largely an art, with judgments often being subjective This model enables a more structured approach to the AE selection process, so that an $A E$ who has potential for successful performance can be selected. Successful performance of the AE is defined as the level of performance which meets the three project objectives relating to quality, budget, and schedule.

A successful AE must be able to produce designs that are functional, within the client's budget, and without delaying the overall project schedule. Good AEs have the proper design capability and ability to interpret the clients' needs. These attributes are essential because unless the design is right, a satisfactory building can never be produced (Kirmani and Baum 1992). In most of the projects apart from selecting good architect and engineer who seems to be skilled in their own arena when work 
together won't be able to perform because of many reasons. There may be several reasons for the conflict which arise between the engineer and the architect. In case of successful project management both engineer and architect should go hand in hand in doing the task assigned to them without having any prejudice. Ultimately both architect and engineer should work towards the goal i.e., in satisfying the clients need.

\section{DECISION SUPPORT SYSTEM}

A decision support frame work in order to select the candidate selection for performing various activities of the project needs to be judged carefully, as projects are unique entities. So the personnel who perform the job should meet the job demands. In most of the construction project performance keeps dropping form the beginning to the end of the project due to fatigue, staying faraway from the family in case of projects like road development, dam construction, canal construction etc,. Several projects in which tasks like dredging, filling, hammering piles require skilled manpower, as well as good machineries. So a balance is required in selecting the methodology, selecting the team members, selection of methodology in procuring materials, handling finance etc.,

The contractor selection issue is normally one of identifying a contractor who can undertake the client's project, and take it to satisfactory conclusion, that is, to meet the client's time, cost, and quality expectations (Holt et al. 1994a; $\mathrm{Ng}$ and Skitmore 1995). Earlier investigations into the subject have attempted to redress existing weaknesses in the contractor selection process (i.e., "lowest-prices" selection preference and subjective judgment) and offer rationalized alternative(s) to the present practice (e.g., Hunt et al. 1966; Hardy et al. 1981; Lewis 1981; Martinelli 1986).

(Chee Hong Wong 2006) discussed on the application of the logistic regression (LR) technique along with its potential for use in a contractor performance prediction during the tender evaluation process. Therefore, the locus of discussion shifts from the comparison with foregoing selection methods, to the theoretical debates of the potential use of the LR technique and its advantages for predicting contractor performance using a case study approach.

Several Methods are available for decision making. Decisions involved in construction industry are complex as it is clouded with lot of uncertainties. Labourers in this sector are more of illiterate in nature. Decision makers always require an effective way to structure their decisions. Analytical Hierarchy Process (AHP) is a simple tool used for multi-criteria decision making. Aiding decisions is the activity of the person who, through the use of explicit but not necessarily completely formalized models, helps obtain elements of responses to the questions posed by a stakeholder in a decision process. These elements work towards clarifying the decision and usually towards recommending, or simply favoring, a behavior that will increase the consistency between the evolution of the process and this stakeholder's objectives and value system.

\section{THE ANALYTIC HIERARCHY PROCESS}

The Analytic Hierarchy Process (AHP) developed by Thomas L. Saaty (1994) is a multi- objective decision making technique that employs a method of pair-wise comparison to rank order alternatives of a problem formulated in a hierarchic structure. AHP organizes the basic problem into its smaller constituent paths and guides the decision maker through a series of pairwise comparison judgements to express a relative strength of the elements in the hierarchy. AHP measures the utility function of the decision maker through the determination of a priority vector.

The great advantage of this technique is its ability to handle complex real life problems. AHP differs from other decision making approaches in that it requires the simultaneous use of data and judgement, as opposed to their sequential use in many other models. Greater care and thorough understanding of the problem are required in formulating a given problem into a hierarchic structure, but once this is accomplished, AHP is reasonably easy to apply.

AHP provides great utility in areas where data collection is extremely difficult. The AHP technique can provide a systematic approach in obtaining the relative weights of the decision elements and a measure of the inconsistency in the decision maker's judgement. This would facilitate formulation of appropriate strategies in a complex decision making problem to attain specified multiple objectives .

The Analytic Hierarchy Process is a multi-criteria decision-making aid that uses a hierarchic or network structures to represent a decision problem and then develop priorities for the alternatives based on the decision maker's judgments throughout the system. AHP begins by decomposing a complex decision problem into a hierarchy of sub-problems. The overall objective or focus is shown at the top of the hierarchy followed by levels of attributes and sub-attributes. Alternatives to be considered are placed in the lowest level of the hierarchy.

The following guidelines should be considered when constructing hierarchies. 
1. The no. of levels used should be chosen to effectively reflect the problem athand.

2. The order of the levels should reflect a logical casual relationship between adjacent levels.

3. The number of members in a particular level should be chosen to describe the level in adequate detail but should not cause unnecessary computation complexity.

\section{ASSUMPTIONS OF AHP}

The major assumptions of AHP are

(I) The relative weights of attributes within a level, conditional on each attribute in the immediately preceding level are unidimensional.

(ii) Pairwise judgements of attributes encompass all relevant aspects of importance within the factor.

(iii) Decision makers can evaluate subproblems in an accurate and relatively consistent manner.

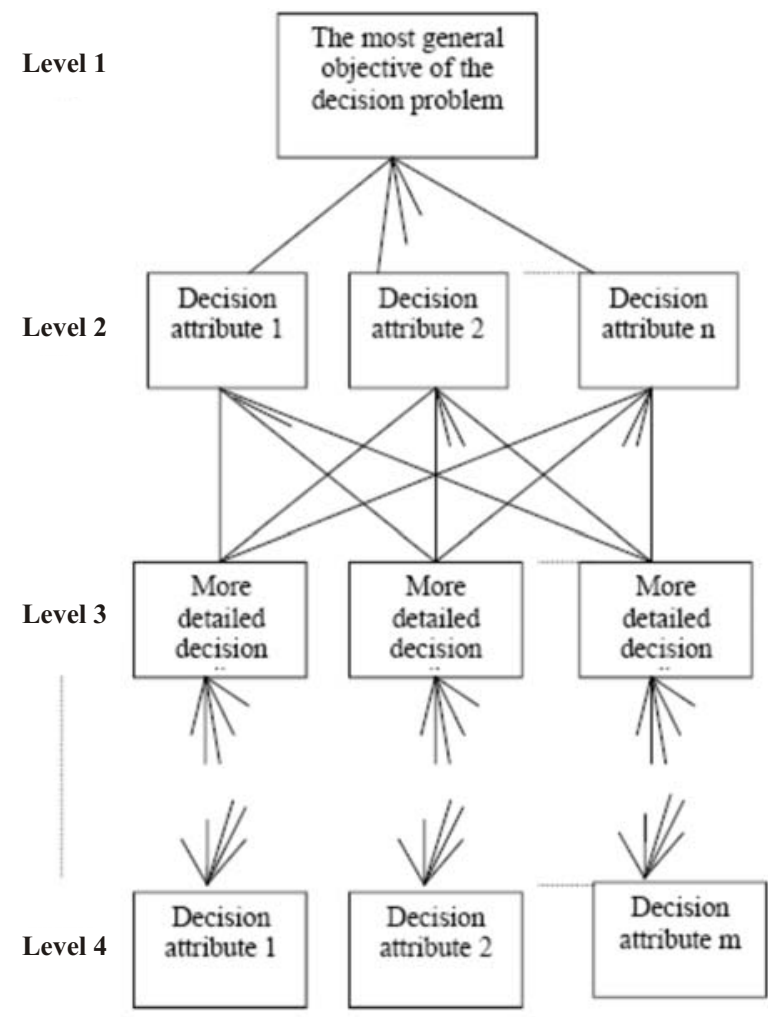

Fig. 1. The Standard Form of Decision Schema in the Analytic Hierarchy Process: a hierarchy with k levels

The standard form of the decision schema shows the various levels in a hierarchy. At level, which is perhaps the most important aspect of the AHP, the decision analyst should break down the decision problem into a hierarchy of interrelated decision elements. At the top of hierarchy lies the most macro decision objective, such as the objective of making the best decision (or selecting the best alternative). The lower levels of the hierarchy contain attributes and subattributes, which contribute to the quality of the decision. Details of these attributes increase at the lower levels of the hierarchy. The last levels of the hierarchy contain decision alternatives on selection choices.

\section{STEPS OF THE PROCESS}

Using AHP in solving a decision problem involves four steps:

Step 1: Setting up the decision hierarchy by breaking down the decision problem into a hierarchy of interrelated decision elements.

Step 2: Collecting input data by pairwise comparisons of decision elements.

Step 3: Using the "Eigen value" method to estimate the relative weights of decision elements. Determination of indicators of consistency in making pairwise comparisons.

Step 4: Aggregating the relative weights of decision elements to arrive at a set of ratings for the decision alternations.

Step 1: Define the problem and determine the objectives. In setting up the decision hierarchy, the number of levels depends on the complexity of the problem and on the degree of detail the analyst requires to solve the problem. Since each level entails pairwise comparison of its elements, the number of elements at each level should be limited to a maximum of nine. This constraint, however, is not a necessary condition of the method and has not been adhered to in all applications.

Step 2: The input data for the problem consists of matrices of pairwise comparisons of elements of one level that contribute to achieving the objectives of the next higher level. There are $n(n-1) / 2$ judgements required to develop the set of matrices. Decision-marks choose a value from Saaty's scale to express the relative significance of one alternative over another. All of the pairwise comparison values can be summarized in a comparison matrix, from which the relative weights of all the alternatives can be extracted. Pairwise comparisons give the evaluator a basis on which to reveal his on her preference by comparing two elements. Also the evaluator has the option of expressing preferences between any two preferences with intermediate values. 
Step 3: The solution technique of the AHP takes in as input the above pairwise comparisons and produces the relative weights of elements at each level as output using the solution methodology. Check for the consistency in the judgements at each level, which helps to revise the judgement in case of inconsistent to avoid inaccuracies in the result obtained.

Step 4: Aggregates the relative weights of various levels obtained from Step-3 in order to produce a vector of composite weights which serve as ratings of decision alternatives (or selection choices) in achieving the most general objective of the problem. These composite weights may also be called decision alternatives scores and they form the basis for selecting an alternative.

\section{SOLUTION METHODOLOGY}

All of the pair-wise comparison values can be summarized in a comparison matrix, from which the relative weights of all the alternatives can be extracted. Eqn.(1) is a comparison matrix from which are can see that, for $n$ criteria, the pairwise comparison of element I to element $j$ has are of the numerical value from Saaty's table called $a_{i j}$.

Table 1. Saaty's Scale

\begin{tabular}{|c|l|}
\hline Relative importance & \multicolumn{1}{|c|}{ Definition } \\
\hline 1 & Equal importance \\
\hline 3 & Weak importance over other \\
\hline 5 & Strong importance \\
\hline 7 & Demonstrated importance over other \\
\hline 9 & Absolute importance \\
\hline $2,4,6,8$ & Intermediate values between \\
\hline
\end{tabular}

The pair wise comparison matrix of criteria can be obtained as follows (Note that $\mathrm{a}_{\mathrm{ji}}=1 / \mathrm{a}_{\mathrm{i}}$ )

$$
C M_{n}=\left[\begin{array}{lll}
a_{11} & a_{12} & a_{1 n} \\
a_{21} & a_{22} & a_{2 n} \\
a_{n 1} & a_{n 2} & a_{n n}
\end{array}\right]
$$

From the comparison Matrix (CM), the principal Eigen vector is computed, and after normalizing, it becomes the vector of priorities. In the absence of a large-scale computer to solve the problem exactly, a method is applied as an approximation of the principal eigenvector. First the geometric means of the $i^{\text {th }}$ row, called $m_{i}$ is calculated:

$$
\mathrm{m}_{\mathrm{i}}=\left[\prod_{\mathrm{j}=1}^{\mathrm{n}} \mathrm{a}_{\mathrm{ij}}\right]^{1 / \mathrm{n}}
$$

where $a_{i j}$ is the element in the comparison matrix standing for the comparison of the $i^{\text {th }}$ to the $j^{\text {th }}$ criteria and $n$ is the total no. of criteria. The relative weight of priorities, $p_{\mathrm{j}}$, is defined as the normalized geometric means of the rows in the comparison matrix:

$$
\mathrm{p}_{\mathrm{j}}=\mathrm{m}_{\mathrm{j}} / \sum_{\mathrm{i}=1}^{\mathrm{n}} \mathrm{m}_{\mathrm{i}} \text {. }
$$

$P V=\left(p_{1}, \ldots ., p_{n}\right)^{\top}$ forms a principal eigen vector for $n$ criteria. Also, for $m$ alternatives, there is an $m \times m$ comparison matrix on each criterion. Each matrix can also have a geometric means of the relative weights of the priorities. The only difference is that now $p_{i j}$ stands for relative weight of priorities for the $\mathrm{i}^{\text {th }}$ alternative with respect to the $j^{\text {th }}$ criterion. Then, $p_{i j}$ forms a new priority matrix called PM. The final weight of the alternative is computed as follows:

\section{$\mathrm{R}=\mathrm{PM} \times \mathrm{PV}$}

$$
=\left[\begin{array}{ccccc}
\mathrm{p}_{11} & \mathrm{p}_{12} & \ldots . . & \mathrm{p}_{1(\mathrm{n}-1)} & \mathrm{p}_{\mathrm{in}} \\
\ldots . & \ldots . . & \ldots . . & \ldots . . & \ldots \\
\mathrm{p}_{\mathrm{m} 1} & \mathrm{pm} 2 & \ldots . . & \mathrm{p}_{\mathrm{m}(\mathrm{n}-1)} & \mathrm{p}_{\mathrm{mn}}
\end{array}\right]\left[\begin{array}{c}
\mathrm{p}_{1} \\
\mathrm{p}_{2} \\
\ldots . . \\
\mathrm{p}_{\mathrm{n}-1} \\
\mathrm{p}_{\mathrm{n}}
\end{array}\right]
$$

$=\left[r_{1}, \ldots ., r_{m}\right]$

where $n$ is the no of criteria and $m$ is the no. of alternatives. In Eq. (4), $p_{i j}(i=1, \ldots, m ; j=1, \ldots ., n)$ represents the relative weight of priority for the $i^{\text {th }}$ alternative with respect to the $j^{\text {th }}$ criterion, $p_{j}(j=1, \ldots, n)$ represents the relative weights of priorities for the $j^{\text {th }}$ criterion, $R$ is a resultant vector, and $\max \left(r_{i}\right), i=1, \ldots, m$, is the best ranking alternative for the overall satisfaction of all criteria.

To verify the consistency of the result, the maximum or principal Eigen value called ${ }_{\text {max }}$ is calculated. Again, there exists difficulties in calculating $\max _{\text {ax }}$ exactly; thus, a method is applied as an approximation of max . First, the matrix of comparison is multiplied on the right by the estimated Eigen vector PV and a new vector $\mathrm{PV}^{\prime}$ is obtained. 
$\mathrm{PV}^{\prime}=\mathrm{CM} \times \mathrm{PV}$

Each $p_{i}^{\prime}$ is $P V^{\prime}$ is divided by the corresponding component in PV, thus obtaining another vector. Taking the sum of the components in this vector and dividing by the number of components giving an approximation to ${ }_{\max }{ }_{\max }$ is always greater than or equal to $n$. The closer ${ }_{\text {max }}$ is to $n$ (the number of components in the matrix), the more consistent is the result. The steps can be represented by the following equation:

$$
\lambda_{\max }=\frac{\sum_{j=1}^{n}\left(p_{j}^{1} / p_{j}\right)}{n}
$$

Next, from ${ }_{\text {max }}$ is calculated the consistency Index $(\mathrm{Cl})$ by the following equation:

$\mathrm{Cl}=\left(_{\max }-\mathrm{n}\right) /(\mathrm{n}-1)$

Given the fact that $\mathrm{Cl}$ depends greatly on the size of the matrix, this value is standardized, whereby it is divided by a Random Index (RI) generated by Oak Ridge National Laboratory. The RI for matrices of order 1-15 is shown in Table 2.

Table 2. Random Index Table

\begin{tabular}{|c|c|c|c|c|c|c|c|c|c|c|c|c|c|c|c|}
\hline $\begin{array}{c}\text { Matrix } \\
\text { order }\end{array}$ & 1 & 2 & 3 & 4 & 5 & 6 & 7 & 8 & 9 & 10 & 11 & 12 & 13 & 14 & 15 \\
\hline R.L & 0.00 & 0.00 & 0.58 & 0.90 & 1.12 & 1.24 & 1.32 & 1.41 & 1.45 & 1.48 & 1.49 & 1.51 & 1.56 & 1.57 & 1.59 \\
\hline
\end{tabular}

Based on $\mathrm{Cl}$ and $\mathrm{RI}$, the Consistency Ratio (CR) is obtained, as follows:

$\mathrm{CR}=\mathrm{Cl} / \mathrm{RI}$

Usually, a CR of 0.10 or less is considered acceptable. If $\mathrm{CR}$ is approximately equal to xero, then the judgement is perfectly consistent. If $\mathrm{CR}$ lies between 0.10 to 0.20 , then the judgement is tolerate. If CR exceeds 0.20 , then the judgement should be revised.

Table 3. Candidate selection

\begin{tabular}{|c|c|c|}
\hline & Primary Criteria & Sub-Criteria \\
\hline \multirow{6}{*}{ 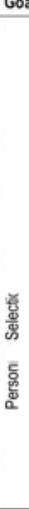 } & Personal Details & $\begin{array}{l}\text { - Gender } \\
\text { - Age } \\
\text { - Manital Status } \\
\text { - Heaith } \\
\text { - Family background }\end{array}$ \\
\hline & Academic Background & $\begin{array}{l}\text { E Educational qualificaton } \\
\text { - Academic Performance }\end{array}$ \\
\hline & Tecthical Capability & $\begin{array}{l}\text { - Analyical Skill } \\
\text { : Logical Reasoning } \\
\text { Knowledge of the discopine }\end{array}$ \\
\hline & Managenial Capability & $\begin{array}{l}\text { - Leadership quafication } \\
\text { - communicaton } \\
\text { - Peam Work } \\
\text { Planning \& Execution }\end{array}$ \\
\hline & Personal Effectiveness & $\begin{array}{l}\text { : Seff-confidence } \\
\text { : Atstude } \\
\text { : Flexbility } \\
\text { Personal Ethics }\end{array}$ \\
\hline & Experience & $\begin{array}{l}\text { - Specialist in a single job } \\
\text { - Variety of Jobs Handled }\end{array}$ \\
\hline
\end{tabular}

The above table indicates a selection of personnel for a construction company. Normally a candidate selection for a job requires lot of parameters need to satisfied. These parameters can be called as primary criteria, which may be further broken down into subcriteria. A pair wise comparison may be tabulated for each of the criteria and may be rated. For selecting a candidate for the post of site engineer a list of criteria may be selected and prioritized. Based on the prioritization obtained from the list of criteria a decision may be taken finally which will be logical and sound.

\section{CONCLUSION}

Performance measure being one of the important criteria in effective management of projects, efforts should be taken to record performance on a periodic basis on various issues. More advanced tools are available to aid us in recording performance. These data obtained form scientific methods which are used for decision making will prove to be scientific in aiding decision making in improving performance of individuals and thus the overall project performance.

\section{REFERENCES}

[1] Barraza, G. A., Back, W. E., and Mata, F. (2004). "Probabilistic forecasting of project performance using stochastic S curves." J. Constr. Eng.Manage., 130(1), 25-32.

[2] Borman, W. C. _1991_. "Job behavior, performance, and effectiveness." Handbook of industrial and organizational psychology, 2nd Ed., M. D. Dunnette and L. M. Hough, eds., Vol. 2, Consulting Psychologists, Palo Alto, Calif., 271-326.

[3] Chee Hong Wong (2004) Journal of Construction Engineering and Management, Vol. 130, (5) $691-698$

[4] Dainty, A. R. J., Cheng, M. I., and Moore, D. R. _2003_. "Redefining performance measures for construction project managers: an empirical evaluation." Constr. Manage. Econom., 21, 209-218.

[5] Holt, G. D., Olomolaiye, P. O., and Harris, F. C. (1994b). "Applying multi-attribute analysis to contractor selection decisions." Eur. J. Purchasing Supply Manage., 1(3), 139-148.

[6] Hunt, H. W., Logan, D. H., Corbetta, R. H., Crimmins, A. H., Bayard, R. P., Love, H. E., and Bogen, S. A. (1966). "Contract award practices." J. Constr. Div., Am. Soc. Civ. Eng., 92(1), 1-16. 
[7] Ireland, V. (2004). "Improving staff performance."

[13] Viswesvaran, C., Ones, D. S., and Schmidt, F. L. Constr. Manage. Econom. 22(2), 121.

[8] Kirmani, S. S., and Baum, W. C. (1992) The consulting profession in developing countries, World Bank, Washington, D.C.

[9] Maloney, W. F. (1990). "Framework for analysis of performance." J. Constr. Eng. Manage., 116(3), 399-415.

[10] Meyer, J., Paunonen, S. V., Gellatly, I., Goffin, R., and Jackson, D. _1989_. "Organizational commitment and job performance: It's the nature of the commitment that counts." J. Appl. Psychol., 74, 152-156.

[11] Moore, D., Cheng, M. I., and Dainty, A._2003_. "What makes a superior management performer: the identification of key behaviours in superior construction managers?" $C / Q$, Construction Paper, 155, 6-9.

[12] Viswesvaran, C. _1993_. "Modeling job performance: Is there a general factor?" Doctoral dissertation, Univ. of lowa, lowa City, lowa. _1996_. "Comparative analysis of the reliability of job performance ratings." J. Appl. Psychol., 81, 557-574.

[14] Sink, D. (1985). Productivity management: Planning, measurement and evaluation, control and improvement. John Wiley and Sons, New York, N.Y.

[15] Thomas L Saaty (1994) "Fundamentals of Decision Making and Priority Theory With the Analytic Hierarchy Process" RWS Publications

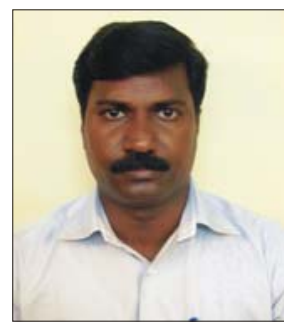

Mr. Niranjan Kumar is a Research Scholar at the Faculty of Civil Engineering, Anna University, Chennai and a Senior Lecturer at the Department of Civil Engineering, Sathyabama University, Chennai. His area of specialization is "Construction Management". He has over eight years of teaching experience and his areas of interest include Risk management, Value management, and Construction Techniques. 